\title{
Clinical utility gene card for: Glanzmann thrombasthenia
}

\section{This article has been corrected since Online Publication and a corrigendum is also published in this issue}

\author{
Mathieu Fiore ${ }^{1}$, Alan T Nurden ${ }^{\star 1}$, Paquita Nurden $^{1}$ and Uri Seligsohn ${ }^{2}$ \\ European Journal of Human Genetics (2012) 20, doi:10.1038/ejhg.2012.151; published online 11 July 2012
}

\section{DISEASE CHARACTERISTICS}

1.1 Name of the disease (synonyms)

Glanzmann thrombasthenia (Glanzmann-Naegeli syndrome, platelet $\alpha \mathrm{IIb} \beta 3$ deficiency, platelet fibrinogen receptor deficiency).

\subsection{OMIM\# of the disease \\ 273800 .}

\subsection{Name of the analyzed genes or DNA/chromosome segments} ITGA2B ( $\alpha$ IIb) and ITGB3 $(\beta 3)$ - chromosome 17q21.32.

\subsection{OMIM\# of the gene(s)}

607759 (ITGA2B) and 173470 (ITGB3).

\subsection{Mutational spectrum}

Glanzmann thrombasthenia (GT) is a rare autosomal recessive disorder caused by the absence or the dysfunction of the $\alpha \operatorname{IIb} \beta 3$ integrin (formerly termed the GPIIb-IIIa complex) on the platelet surface. The most abundant receptor on platelets, $\alpha \operatorname{IIb} \beta 3$, mediates platelet aggregation through its binding of adhesive proteins, such as fibrinogen, von Willebrand factor, vitronectin and fibronectin. ${ }^{1}$ First described in 1918 by Glanzmann as 'hereditary hemorrhagic thrombasthenia', this disease is characterized by spontaneous and trauma-related mucocutaneous bleeding, with variable expression ranging from easy bruising to fatal hemorrhages. ${ }^{2}$ Heterozygotes are asymptomatic.

The ITGA2B gene encodes for the $\alpha$ IIb subunit, whereas the ITGB3 gene encodes for $\beta 3$. ITGA2B spanning $17 \mathrm{~kb}$ has 30 exons, whereas ITGB3 has 15 exons, but spans $46 \mathrm{~kb}$; they are closely located on chromosome $17 \mathrm{q} 21.32$ without evidence for coordinated expression. ${ }^{3}$ Mutations causing GT affect either ITGA2B or ITGB3. As GT is an autosomal recessive disease, patients are mostly compound heterozygotes for ITGA2B or ITGB3 mutations in the absence of consanguinity. An Internet database (http://med.mssm.edu/ glanzmanndb) that is regularly updated contains clinical, biological and genetic data in referenced patients. To date, more than 150 different mutations have been described, with a tendency for more mutations in ITGA2B, perhaps reflecting its higher number of exons. GT is caused by a wide spectrum of defects, including nonsense, missense, splice site mutations, and less commonly, small insertions and deletions. ${ }^{3}$ Large deletions are rare.
Whereas expression of $\alpha \mathrm{IIb}$ is specific to the megakaryocyte lineage, $\beta 3$ has a widespread tissue distribution as part of the vitronectin receptor $(\alpha \mathrm{v} \beta 3)$. Despite the wider expression of the $\beta 3$ subunit, the bleeding phenotype continues to dominate for ITGB3 mutations. In rare patients, gain-of-function mutations in either ITGA2B or ITGB3 can also interfere with megakaryocytopoiesis and lead to platelet anisocytosis and moderate thrombocytopenia. ${ }^{3}$

\subsection{Analytical methods}

The anucleate platelet contains low amounts of RNA that is often unstable; therefore, mutation screening in GT is largely based on DNA analysis. A range of DNA screening methods have been described, including PCR single-strand conformation polymorphism analysis and denaturing gradient gel electrophoresis. ${ }^{4}$ More recently, highresolution melting (HRM) screening has been used. ${ }^{5}$ Nonetheless, none of these methods are $100 \%$ guaranteed, and standard PCR of genomic DNA followed by direct sequencing of essential coding and flanking regions of both ITGA2B and ITGB3 is recommended.

\subsection{Analytical validation}

Analyses of mutated and non-mutated control samples are recommended. Quality control is also important, particularly for DNA isolated in different laboratories. Both strands of DNA should be sequenced and variations confirmed by an independent method (eg, restriction enzyme analysis, ASA-PCR; HRM and so on) and/ or by DNA sequencing of a second sample..$^{5}$ Identified variations can be directly compared with available databases and bioinformatic softwares, to establish whether they correspond to known mutations and to assess their potential pathological nature. Transmission of the mutation(s) should be established by analysis of family members whenever possible. Molecular modeling on the basis of the known crystal structure of the $\alpha \operatorname{Ib} \beta 3$ and $\alpha \mathrm{v} \beta 3$ extracellular domains can help to assess the effect of missense mutations on integrin structure. ${ }^{6,7}$ Expression of recombinant mutated integrin in heterologous cell lines can be informative on expression and function, but is only available on a research basis in specialized laboratories. RT-PCR may be used to confirm potential splicing defects of RNA expression. Large deletions may be looked for by quantitative multiplex fluorescence-PCR, especially when standard DNA sequencing reveals a single heterozygous mutation in a patient with a clear GT phenotype.

\footnotetext{
${ }^{1}$ Centre de Référence des Pathologies Plaquettaires, Plateforme Technologique d'Innovation Biomédicale, Hôpital Xavier Arnozan, Pessac, France; ${ }^{2}$ Amalia Biron Research Institute of Thrombosis and Haemostasis, Chaim Sheba Medical Center, Tel-Hashomer and Sackler Faculty of Medicine, Tel Aviv University, Tel Aviv, Israel

${ }^{*}$ Correspondence: Dr AT Nurden, Centre de Référence des Pathologies Plaquettaires, Plateforme Technologique d'Innovation Biomédicale, Hôpital Xavier Arnozan, Pessac 33600, France. Tel: + 33 (0)5 571028 51; Fax: + 33 (0)5 571028 64; E-mail: nurdenat@gmail.com
} 
1.8 Estimated frequency of the disease (incidence at birth ('birth prevalence') or population prevalence) Unknown. No epidemiological data are currently available for GT on a world-wide basis. ${ }^{8}$ It is more common in Europe and the Middle East than in the United States, and is clustered within certain ethnic groups (see below). In France, a recent census suggests approximately 300 cases, half of whom are of Manouche Gypsy origin and share the same mutation (M Fiore, data not published).

\subsection{If applicable, prevalence in the ethnic group of investigated persons}

GT occurs in high frequency in certain ethnic populations, with an increased incidence of consanguinity, such as Iraqi Jews, Palestinian Arabs or Jordanian Arabs. ${ }^{9,10}$ The unusual high frequency of GT among these groups is largely the result of founder mutations. In France, GT is particularly frequent in the Gypsy population, mainly represented by the Manouche tribe, with a founder mutation estimated by us to have occurred 300-400 years ago. ${ }^{11}$

\subsection{Diagnostic setting}

\begin{tabular}{lcc} 
& Yes & No \\
A. (Differential) diagnostics & $\bigotimes$ & $\square$ \\
B. Predictive Testing & $\square$ & $\square$ \\
C. Risk assessment in relatives & $\bigotimes$ & $\square$ \\
D. Prenatal & $\bigotimes$ & $\square$ \\
\hline
\end{tabular}

Comment:

A. Although very rare, acquired thrombasthenia has been reported in leukemia with chromosome 15-17 translocations; it is more commonly associated with autoantibodies directed against $\alpha \operatorname{IIb} \beta 3$, some of which also induce thrombocytopenia, as well as blocking $\alpha \operatorname{IIb} \beta 3$ function. ${ }^{12,13}$ It is also to be noted that some anti-thrombotic therapies involve the use of $\alpha \mathrm{IIb} \beta 3$ blocking drugs that transiently induce a GT-like state.

In leukocyte adhesion deficiency-3, patients manifest a bleeding phenotype with immune deficiency and recurrent infections, but demonstrate a normal expression of $\beta 3$ integrins. Mutations in the FERMT3 gene (encoding kindlin-3) account for the phenotype. ${ }^{14}$ Kindlin-3 belongs to a family of proteins that cooperate in integrin activation. ${ }^{3}$

Platelet aggregation defects restricted to specific agonists may imply abnormalities of a signaling pathway and should be distinguished from GT, where aggregation is defective for all physiological agonists in the presence of a normal platelet number and size. GPIb-related function as assessed by ristocetin-induced platelet agglutination is normal, although it can be cyclic.

B. To date, studies have failed to find any correlation between frequency and severity of bleeding and the nature of the gene defect in GT. Bleeding tendencies can differ considerably between affected persons, even within the same family or ethnic group. ${ }^{3}$

C. Mutation screening in patients and family members is essential for genetic counseling, for most patients will have their own private mutation (unless in an ethnic group). DNA analysis allows identification of asymptomatic heterozygous carriers, as these cannot be identified with certainty by phenotypic studies alone. ${ }^{4}$ Expression of $\alpha \operatorname{Ilb} \beta 3$ in platelets of normal healthy subjects is known to vary by more than two-fold.

\section{TEST CHARACTERISTICS}

\begin{tabular}{|c|c|c|c|c|}
\hline & \multicolumn{2}{|c|}{ Genotype or disease } & \multirow{2}{*}{$\begin{array}{l}\text { A: True positives } \\
\text { B: False positives }\end{array}$} & \multirow{2}{*}{$\begin{array}{l}\text { C: False negative } \\
\text { D: True negative }\end{array}$} \\
\hline & Present & Absent & & \\
\hline \multicolumn{5}{|l|}{ Test } \\
\hline Positive & $A$ & B & $\begin{array}{l}\text { Sensitivity: } \\
\text { Specificity: }\end{array}$ & $\begin{array}{l}A /(A+C) \\
D /(D+B)\end{array}$ \\
\hline Negative & C & $\mathrm{D}$ & $\begin{array}{l}\text { Positive predictive value: } \\
\text { Negative predictive value: }\end{array}$ & $\begin{array}{l}A /(A+B) \\
D /(C+D)\end{array}$ \\
\hline
\end{tabular}

\subsection{Analytical sensitivity}

(proportion of positive tests if the genotype is present)

For cases with a classic GT phenotype, the success of mutation analysis by DNA sequencing of ITGA2B and ITGB3 ranges from 80 to $90 \%$. Other possible causes of GT, such as miRNAs and intronic mutations, are not currently researched, although an involvement of other genes (eg, chaperone defects) cannot be ruled out. Once a mutation is found the success of genotyping should be $100 \%$.

\subsection{Analytical specificity}

(proportion of negative tests if the genotype is not present)

Genetic testing is expected to be negative in the absence of the disease with a specificity of $100 \%$. However, both $\alpha \mathrm{IIb}$ and $\beta 3$ are polymorphic glycoproteins, so that each new amino acid substitution has to have its pathogenicity proven (or non-proven).

\subsection{Clinical sensitivity}

(proportion of positive tests if the disease is present)

The clinical sensitivity can be dependent on variable factors, such as age or family history. In such cases, a general statement should be given, even if a quantification can only be made case by case.

A sensitivity of $100 \%$ for patients with a classical GT phenotype of the disorder (absence of platelet aggregation and $\alpha \mathrm{IIb} \beta 3$ expression) can be achieved. However, some mutations may only partially block integrin expression/function, and consequently the bleeding syndrome can be negligible. In such cases, the characterization of $\alpha \mathrm{IIb} \beta 3$ may require specialized procedures. The clinical severity of GT tends to diminish with age, although the bleeding manifestations persist and are life-long.

\subsection{Clinical specificity}

(proportion of negative tests if the disease is not present)

The clinical specificity can be dependent on variable factors, such as age or family history. In such cases, a general statement should be given, even if a quantification can only be made case by case.

In the absence of GT the proportion of negative tests is expected to be high, although the prevalence of other disorders interfering with platelet function is relatively high, and mucocutaneous bleeding is symptomatic for all of them.

\subsection{Positive clinical predictive value} (life-time risk of developing the disease if the test is positive) Not applicable. GT shows complete penetrance, and most patients are diagnosed at birth or during early infancy. ${ }^{2}$

\subsection{Negative clinical predictive value} (probability of not developing the disease if the test is negative) If an index case has been genotyped negatively (with normal platelet function and full $\alpha \operatorname{IIb} \beta 3$ expression), the probability of not developing the disease by the propositus and other family members is $100 \%$. 
Even if an index case in a given family has not been tested genetically, phenotypic characterization can exclude the diagnosis in $100 \%$ of family members. However, this is not the case if members of the family have another bleeding disorder. In such a case, genetic analysis is indispensable.

\section{CLINICAL UTILITY}

3.1 (Differential) diagnosis: The tested person is clinically affected (To be answered if in 1.10 'A' was marked)

\subsubsection{Can a diagnosis be made other than through a genetic test?}

\begin{tabular}{lll}
\hline No & $\square$ (continue with 3.1.4) \\
Yes & $\bigotimes$ & \\
& Clinically & \\
& Imaging & $\square$ \\
& Endoscopy & $\square$ \\
& Biochemistry & $\square$ \\
& Electrophysiology & $\square$ \\
& Other (please describe) & Platelet function testing
\end{tabular}

\subsubsection{Describe the burden of alternative diagnostic methods to the patient}

GT is readily identifiable by platelet function testing, and a lack of platelet aggregation in response to all physiological agonists, such as $\mathrm{ADP}$, collagen, epinephrine or thrombin, is unique for this disease. Clot retraction is also abnormal for most patients with GT. Flow cytometry allows rapid identification of both $\alpha \operatorname{IIb} \beta 3$ deficiency and (with specific tests) non-functional $\alpha \operatorname{IIb} \beta 3 .{ }^{1}$ These provide minimal inconvenience to the patient and can be performed with $10-30 \mathrm{ml}$ blood. However, only DNA analysis can confirm that the disease is caused by a genetic defect.

\subsubsection{How is the cost effectiveness of alternative diagnostic methods to be judged?}

There are no studies available to determine the cost effectiveness of alternative diagnostic approaches to GT. Nevertheless, biological analyses have to be performed in a specialized laboratory and their cost effectiveness is high. Moreover, platelet samples must be processed and analyzed within $4 \mathrm{~h}$ of blood collection, which is not always possible when they are sent from far away. So, often the patient has to visit a specialized center. In contrast, samples for DNA testing can be sent by mail.

\subsubsection{Will disease management be influenced by the result of a genetic test?}

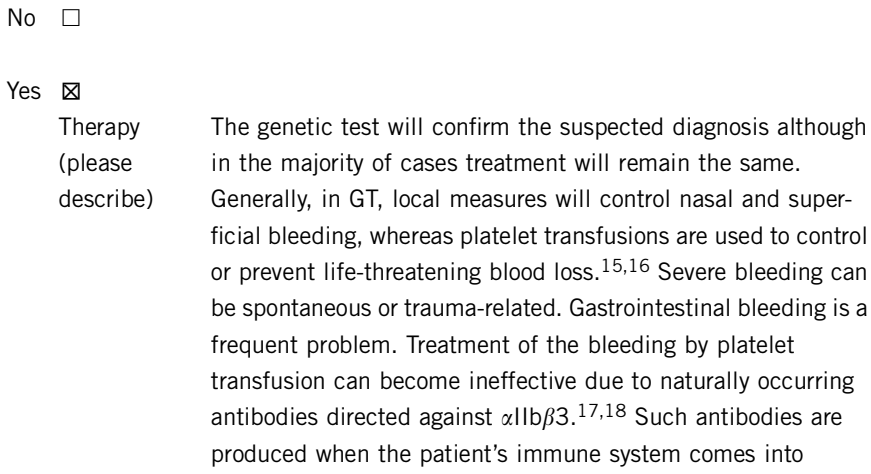

contact with normal platelets (after transfusion, pregnancy) Activated recombinant factor VII ( $\mathrm{rFVIIa)} \mathrm{provides} \mathrm{an} \mathrm{alternative}$ treatment for GT patients who develop such antibodies. ${ }^{19}$ Patients with mutations causing absence or premature termination of $\alpha$ llb or $\beta 3$ are particularly prone to form antibodies against $\alpha \operatorname{llb} \beta 3.20$ This finding may help in deciding whether platelet transfusion or rFVIla should be used. There is no evidence as yet that knowing the mutation will affect prognosis or management of the disease although the choice of therapy may be influenced by the presence of inhibitors.

3.2 Predictive Setting: The tested person is clinically unaffected but carries an increased risk based on family history

(To be answered if in 1.10 'B' was marked)

\subsubsection{Will the result of a genetic test influence lifestyle and prevention? \\ No.}

3.2.2 Which options in view of lifestyle and prevention does a person at-risk have if no genetic test has been done (please describe)? Not applicable.

3.3 Genetic risk assessment in family members of a diseased person (To be answered if in 1.10 ' $\mathrm{C}$ ' was marked)

\subsubsection{Does the result of a genetic test resolve the genetic situation in} that family?

Yes. If mutations were found and shown to be responsible for the disease, then no further tests are necessary.

\subsubsection{Can a genetic test in the index patient save genetic or other} tests in family members?

No. Even in the case of known familial mutations, carriers need to be individually identified (or excluded). Heterozygous expression is asymptomatic.

3.3.3 Does a positive genetic test result in the index patient enable a predictive test in a family member?

Yes, DNA testing can be rapid, as it is restricted to the identified mutation.

\subsection{Prenatal diagnosis}

(To be answered if in 1.10 'D' was marked)

\subsubsection{Does a positive genetic test result in the index patient enable a} prenatal diagnosis?

Prenatal diagnosis is possible, but testing requires special procedures, such as chorionic villi sampling. Fetal blood sampling should be avoided, as it can lead to death due to bleeding in affected fetuses. ${ }^{21-23}$

\section{IF APPLICABLE, FURTHER CONSEQUENCES OF TESTING}

Please assume that the result of a genetic test has no immediate medical consequences. Is there any evidence that a genetic test is nevertheless useful for the patient or his/her relatives? (Please describe)

Diagnosis of GT is based first on the clinical and phenotypic characterization, including specific biological studies designed to assess quantitative and qualitative deficiencies of $\alpha \operatorname{IIb} \beta 3$. Biological testing originally resulted in the classification of GT into three 
subtypes: type I with little or no expression of $\alpha \mathrm{IIb} \beta 3$, no fibrinogen in $\alpha$-granules and no clot retraction; type II with 5 to $20 \% \alpha \operatorname{IIb} \beta 3$, and as a consequence, fibrinogen in $\alpha$-granules and a subnormal to normal clot retraction; and variant GT with $50 \%$ or more of the normal expression of $\alpha \mathrm{IIb} \beta 3$ unable to support aggregation. ${ }^{2}$ Nonetheless, genetic testing should be proposed to families because: (i) a positive test helps to remove any doubt in the diagnosis; (ii) it is essential for carrier detection; the asymptomatic carriers display a normal phenotype; and (iii) in some cases, it may be useful for prediction of anti-platelet antibody formation. Genetic testing also provides more precise information on the cause of the $\alpha \operatorname{Ilb} \beta 3$ deficiency or non-functioning.

\section{CONFLICT OF INTEREST}

The authors declare no conflict of interest.

\section{ACKNOWLEDGEMENTS}

This work was supported by EuroGentest2 (Unit 2: 'Genetic testing as part of health care'), a Coordination Action under FP7 (Grant Agreement Number 261469) and the European Society of Human Genetics.

1 Nurden AT: Glanzmann thrombasthenia. Orphanet J Rare Dis 2006; 1: 10.

2 George JN, Caen JP, Nurden AT: Glanzmann's thrombasthenia: the spectrum of clinical disease. Blood 1990; 75: 1383-1395.

3 Nurden AT, Fiore $M$, Nurden P, Pillois $X$ : Glanzmann thrombasthenia: a review of ITGA2B and ITGB3 defects with emphasis on variants, phenotypic variability, and mouse models. Blood 2011; 118: 5996-6005.

4 Nurden AT, Fiore M, Pillois X, Nurden P: Genetic testing in the diagnostic evaluation of inherited platelet disorders. Semin Thromb Hemost 2009; 35: 204-212.

5 Fiore M, Nurden AT, Vinciguerra C, Nurden P, Pillois X: Rapid diagnosis of the French gypsy mutation in Glanzmann thrombasthenia using high-resolution melting analysis. Thromb Haemost 2010; 104: 1076-1077.

6 Coller BS, Shattil SJ: The GPIIb/IIla (integrin $\alpha \mathrm{llb} \beta 3$ ) odyssey: a technology-driven saga of a receptor with twists and turns and even a bend. Blood 2008; 112: 3011-3025.
7 Xiao T, Takagi J, Coller BS, Wang JH, Springer TA: Structural basis for allostery in integrins and binding to fibrinogen-mimetic therapeutics. Nature 2004; 432: 59-67.

8 Nurden AT: Glanzmann thrombasthenia: the need for epidemiological studies. J Thromb Haemost 2009; 7: 1875-1877.

9 Seligsohn U, Rososhansky S: A Glanzmann's thrombasthenia cluster among Iraqi Jews in Israel. Thromb Haemost 1984; 52: 230-231.

10 Awidi AS: Increased incidence of Glanzmann's thrombasthenia in Jordan as compared with Scandinavia. Scand J Haematol 1983; 30: 218-222.

11 Fiore M, Pillois X, Nurden P, Nurden AT, Austerlitz F: Founder effect and estimation of the age of the French Gypsy mutation associated with Glanzmann thrombasthenia in Manouche families. Eur J Hum Genet 2011; 19: 981-987.

12 Bloor AJ, Smith GA, Jaswon M, Parker NE, Ouwehand WH, Liesner R: Acquired thrombasthenia due to GPIIbllla platelet autoantibodies in a 4-yr-old child. Eur J Haematol 2006; 76: 89-90.

13 Chen Y, Wu QY, Wang Z et al: Abnormalities of platelet membrane glycoproteins in acute nonlymphoblastic leukemia [abstract]. Thromb Haemost 1989; 62: 176.

14 Svensson L, Howarth K, McDowall A et al: Leukocyte adhesion deficiency-III is caused by mutations in KINDLIN3 affecting integrin activation. Nat Med 2009; 15: 306-312.

15 Bolton-Maggs PH, Chalmers EA, Collins PW et al: A review of inherited platelet disorders with guidelines for their management on behalf of the UKHCDO. Br J Haematol 2006; 135: 603-633.

16 Di Minno G, Coppola A, Di Minno MN, Poon MC: Glanzmann's thrombasthenia (defective platelet integrin alphallb-beta3): proposals for management between evidence and open issues. Thromb Haemost 2009; 102: 1157-1164.

17 Santoro C, Rago A, Biondo F et al: Prevalence of allo-immunization anti-HLA and antiintegrin alphallbbeta3 in Glanzmann Thromboasthenia patients. Haemophilia 2010; 16: 805-812.

18 Taaning E, Knudsen FU, Thorsen S, Jonsson V: Immunization against platelet glycoprotein Ilb-IIla in Glanzmann's thrombasthenia. Eur J Haematol 1997; 58 360-361.

19 Poon MC, D'Oiron R, Von Depka M et al: Prophylactic and therapeutic recombinant factor VIla administration to patients with Glanzmann's thrombasthenia: results of an international survey. J Thromb Haemost 2004; 2: 1096-1103.

20 Fiore M, Firah N, Pillois X, Nurden P, Heilig R, Nurden AT: Natural history of platelet antibody formation against alphallbbeta3 in a French cohort of Glanzmann thrombasthenia patients. Haemophilia 2012; 18: e201-e219.

21 Seligsohn U, Mibashan RS, Rodeck CH, Nicolaides KH, Millar DS, Coller BS: Prenatal diagnosis of Glanzmann thrombasthenia. Lancet 1985; 28 : 1419.

22 French DL, Coller BS, Usher S et al: Prenatal diagnosis of Glanzmann thrombasthenia using the polymorphic markers BRCA1 and THRA1 on chromosome 17. Br J Haematol 1998; 102: 582-587.

23 Srivastava A, Usher S, Nelson EJ et al: Prenatal diagnosis of Glanzmann thrombasthenia. Natl Med J India 2003; 16: 207-208. 